\title{
Innovations in low input and organic dairy supply chains-What is acceptable in Europe?
}

\author{
P. K. Nicholas, ${ }^{* 1,2}$ S. Mandolesi,† S. Naspetti, $\neq$ and R. Zanoli† \\ *Institute of Biological, Environmental and Rural Sciences, Aberystwyth University, IBERS Gogerddan Campus, Aberystwyth University, \\ Aberystwyth, SY23 3EE, United Kingdom \\ †Dipartimento di Scienze Agrarie, Alimentari e Ambientali (D3A), Università Politecnica delle Marche, Via Brecce Bianche, Ancona, 60131, Italy \\ ¥Dipartimento di Scienze e Ingegneria della Materia, dell'Ambiente ed Urbanistica (SIMAU), Università Politecnica delle Marche, \\ Via Brecce Bianche, Ancona, 60131, Italy
}

\section{ABSTRACT}

The growth in organic and low-input farming practices is driven by both market demand for high quality, safe food, and European Union policy support, and these types of farming practices are considered in European Union policies for sustainable production, food quality, healthy life, and rural development. However, many constraints to the development of low-input and organic dairy farming supply chains have been identified, including economic, political, and technical constraints. In order for these types of supply chains to develop and provide further benefits to society, innovations are required to improve their sustainability. However, an innovation will only be taken up and result in desirable change if the whole supply chain accepts the innovation. In this paper, Q methodology is used to identify the acceptability of dairy supply chain innovations to low-input and organic supply chain members and consumers in Belgium, Finland, Italy, and the United Kingdom. A strong consensus existed across all respondents on innovations that were deemed as unacceptable. The use of genetically modified and transgenic organisms in the farming system and innovations perceived as conflicting with the naturalness of the production system and products were strongly rejected. Innovations that were strongly liked across all participants in the study were those related to improving animal welfare and improving forage quality to be able to reduce the need for purchased concentrate feeds. Only minor differences existed between countries as to where the priorities lay in terms of innovation acceptability.

Key words: dairy, supply chain, low input, organic, innovation, acceptability, Q methodology

\footnotetext{
Received July 24, 2013.
}

Accepted November 3, 2013.

${ }^{1}$ Corresponding author: pip.nicholas@aber.ac.uk

${ }^{2}$ Current address: Level 2, Stapledon Building, Gogerddan Campus, Institute of Biological, Environmental and Rural Science, Aberystwyth University, Aberystwyth SY233EE, United Kingdom.

\section{INTRODUCTION}

In the rapidly changing environment in which Europe's agri-food industries must prosper, new knowledge-based farming systems are required that are profitable at a farm level, produce competitive food products required in the market place, are environmentally sustainable, and are energy efficient (European Commission, 2008). In dealing with the challenges facing agriculture, such as climate change and biodiversity loss, the multifunctional potential of agricultural systems is now as important as productivity for a sustainable future for European agriculture.

The growth in organic and low-input farming practices is driven by both market demand and European Union (EU) policy support (predominantly agri-environment programs based on environmental benefits) and these farming practices are considered in the EU policies for sustainable production, food quality, healthy life, and rural development (European Communities, 2007; Schmid et al., 2008). In terms of consumer demand, health and food safety concerns [particularly related to chemical residues and genetically modified (GM) food] are the main motives for organic food purchases (Midmore et al., 2005; Padel and Foster, 2005) but ethical concerns, specifically in relation to standards of animal welfare, also play a significant influencing role in the decision to purchase organic food (Harper and Makatouni, 2002). A study by Midmore et al. (2005) identified a range of variables for consumers to select organic and low-input food, including perceived healthiness, purity, naturalness, and the more social values of better environmental care and positive animal welfare. Animal health and animal welfare in particular are considered important by consumers from both an ethical perspective and the perceived impact that it can have with respect to producing safer and healthier food (FAO, 2001; European Commission, 2005, 2007; Midmore et al., 2005; Caroprese et al., 2006; Kjærnes et al., 2007).

Whereas organic dairy farming is clearly defined through European legislation (European Communi- 
ties/834/2007), the concept of low-input farming is not commonly defined, although many studies have developed their own working definitions based primarily on low levels (quantity or cost as an approximation of quantity) of purchased feed, fertilizer, crop protection, percent cropping, milk yield, and stocking rates, and high numbers of days at pasture (CEAS and EFNCP, 2000; EEA, 2005; Janssen et al., 2009). Constraints to the conversion to organic and low-input dairying systems and the development of these sectors have been widely identified (Falconer, 2000; Midmore et al., 2001; Padel, 2001; Makatouni, 2002; Regouin, 2003; Smith and Marsden, 2004; Darnhofer et al., 2005; Smit et al., 2009). Many of them are common across European countries and include economic constraints [e.g., high risk during conversion (Midmore et al., 2001; Moakes and Lampkin, 2009)], the availability and the size of post conversion premiums (Midmore et al., 2001), the availability of support payments (Bayliss and Clay, 2006; Moakes and Lampkin, 2009), and some practical farm management issues, such as the availability (and use) of the appropriate breeds (Knaus 2009, Roche et al., 2009) and feeds (Schiere et al. 1999; Zollitsch et al., 2004; Nicholas et al., 2007), the loss of nitrogen in pasture systems (Ledgard and Luo, 2008), and the challenge of managing animal health and welfare with reduced reliance on veterinary medicines (Nauta et al., 2006; Vaarst et al., 2008). A need exists to develop innovations within low-input and organic dairying to overcome some of these constraints and improve the multifunctional performance of these systems. The applicability of the innovations across a wide geographical area and in a wide range of low-input and organic dairy systems (i.e., cows, sheep, and goats) is important for maximizing the return on investment in research and development.

In order for an innovation to be taken up in an industry and effect desirable change, that innovation must be acceptable to the whole supply chain, including producers, processors, retailers, and consumers. Different actors in the supply chain and consumers may have different views on an innovation, depending on how it is perceived to affect their business or themselves. Supply chain innovations often require costly, new investments and activities and, therefore, firms may be reluctant to participate in an innovation until the risks can be alleviated and clear benefits identified (Bello et al., 2004). Positive externalities related to the environment and animal welfare can be achieved by applying an innovation, but only if it is acceptable to a wide proportion of the industry. To date, most investigations into food innovations have been from the consumer side (Ronteltap et al., 2007) and little literature exists on the acceptance of innovative technologies and products in the agri-food industry along the supply chain. Differing attitudes toward the acceptability of innovations in food supply chains can be partly explained by the fact that food is not simply thought of in functional terms. It is part of a much wider social and psychological setting that includes, among others, attitudes toward human health, the environment, and science; deep-seated values and fundamental world outlook; as well as personal and familial habitual behaviors (Brook Lyndhurst, 2009). In addition, the acceptance of an innovation in farming or supply chain practices is also likely to vary significantly geographically due to differences in climate, traditional farming practices, farm ownership and structure, lengths of supply chains, and supply chain relationships. Cultural differences, including attitudes toward animal welfare, environment, and natural resource availability, can also be relevant. Therefore, our study applied Q methodology (McKeown and Thomas, 2013) to determine the attitudes of low-input and organic dairy supply chain members in 4 European countries [Belgium (BE), Finland (FI), Italy (IT) and the United Kingdom (UK)] to the acceptability of various innovations in dairy farm and dairy supply chain practices.

\section{MATERIALS AND METHODS}

\section{Q Methodology}

The Q methodology was chosen for this study as it enables a systematic study of human subjectivity, where subjectivity refers simply to a person's point of view (McKeown and Thomas, 2013). The methodology is used to gain an in-depth understanding of the perspectives of a specific part of the population and it is not intended to lead to conclusions about the population as a whole (Brown, 1993). In our study, Q methodology was applied to understand the different attitudes of supply chain participants to innovations within organic and low-input dairy supply chains. Although Q methodology is starting to be used in a broader range of research fields (Eden et al., 2008), it is more commonly applied in social science disciplines, including policy analysis, investigating environmental issues, and health research (Barry and Proops, 1999; Eden et al., 2008; Hall, 2008).

Definition of the Research Topic and the Concourse. A Q study starts with the definition of the research topic (Donner, 2001) and the exploration of the discourse surrounding that topic, which in Q methodology is referred to as the concourse. In the current study, the research topic is the acceptability of innovations in dairy farming and dairy supply chain practices to achieve more sustainable low-input and organic dairy farming and supply chain systems. The 
relevant discourse surrounding this particular research topic included materials on innovations across the broad range of dairy farming systems applicable or existing in the participating countries. In this study, the relevant population from which to draw the discourse was quite broad and included all farmers (not only those interested in organic and low-input farming), food and agricultural supply chain members (including consumers), and experts on innovation dissemination and uptake. Different methods were used to generate the concourse, according to McKeown and Thomas (2013). As a primary tool, a short questionnaire on areas of innovations in farming and supply chain management was sent to a selection of key informants in each country. These key informants were asked to specify their point of view concerning the innovations in the organic and the lowinput dairy sector. As a secondary tool, national and international literature was used to generate further statements. The statements from both sources were then combined into 1 concourse for the study, which consisted of over 200 statements.

Development of the Q-Sample. A Q-sample is a collection of representative statements derived from the concourse, which are presented to the respondents for ranking into a quasi-normal distribution (McKeown and Thomas, 2013). For our study, a structured Q-sample was used to systematically select the statements, according to specific theoretical categories. These categories were breeds, feeds, and management and practice on farm and in the supply chain. Due to the multilingual nature of the study and the nature of Q methodology itself, it was necessary to use statements with the same conceptual meaning in each country (Carlson, 2000). To facilitate this, the statements were translated and then back translated into English in each country to ensure that the specific technical nature of each statement was correctly represented. The statements were further refined through 2 pilot studies ( 1 in IT and one in the UK) to test both the language and comprehension of all the statements. Following these pilots, a final list of 34 statements was selected to comprise the Q-sample. According to Brown and Feist (1992), who tested cross-cultural validity by adopting a strategy involving bilingual researchers and respon- dents, a good translation implies Q-sample equivalence. Our procedure should also allow for factor differences (similarities) to be explained as arising from attitudinal differences (similarities) than from a lack of parallelism in translation.

Selection of the Participants. The participant sample is the group of people selected to carry out the Q-sort (explained in detail in the next section) and they were selected from people participating in dairy supply chains, including consumers. A large participant number is not important in Q methodology, because the focus is on the extent to which the subjects are similar and dissimilar to each other (Brown, 1993). McKeown and Thomas (2013) recommend a participant sample of between 50 and 100 individuals.

In this Q study, we planned to gather the Q-sorts and the post-sort discussions in 3 group interviews (consumers, producers, and retailers and processors, with 8 to 12 participants in each) in each country (UK, IT, FI, and $\mathrm{BE}$ ). Recruitment criteria were the same across the all countries. Consumers were recruited among those purchasing dairy products and not living or working on a dairy farm. Quotas were also set for sex, age, and employment. Other supply chain participants were recruited via dairy industry contacts in each country. Due to difficulties with recruitment, some interview sessions had to be conducted in a modified way, either individual interviews (UK and FI processors and retailers) or postal interviews (BE producers). The numbers and types of participants in each country are presented in Table 1.

Ranking of Statements: Q-Sorting. The Qsorting technique is the ranking of a set of stimuli, called the Q-sample, based on a person's own viewpoint, along a continuum (McKeown and Thomas, 2013). Each participant produces a complete Q-sort, in which he/she impressed his/her subjectivity. The Qsorts were gathered in the UK, FI, BE, and IT in the spring and summer of 2012. Participants were required to rank the 34 statements comprising the Q-sample. These statements had to be arranged on a template (Figure 1) in a quasi-normal distribution. The 34 statements had to be sorted from "strongly like" $(+9)$ to "strongly dislike" $(+1)$. The forced distribution used in

Table 1. Supply chain participants (no.) in Belgium, Finland, Italy, and the United Kingdom

\begin{tabular}{lcccc}
\hline Item & Consumers & Producers & Processors/retailers & Total \\
\hline Country & & & & \\
Belgium & 9 & 5 & 7 & 21 \\
Finland & 9 & 9 & 7 & 28 \\
Italy & 8 & 9 & 8 & 24 \\
United Kingdom & 10 & & & 26 \\
Total & & & 99 \\
\hline
\end{tabular}




\begin{tabular}{|c|c|c|c|c|c|c|c|c|}
\hline+1 & +2 & +3 & +4 & +5 & +6 & +7 & +8 & +9 \\
\hline+1 & +2 & +3 & +4 & +5 & +6 & +7 & +8 & +9 \\
\hline \multirow[t]{5}{*}{+1} & +2 & +3 & +4 & +5 & +6 & +7 & +8 & +9 \\
\hline & +2 & +3 & +4 & +5 & +6 & +7 & +8 & \\
\hline & & +3 & +4 & +5 & +6 & +7 & & \\
\hline & & & +4 & +5 & +6 & & & \\
\hline & & & & +5 & & & & \\
\hline
\end{tabular}

Figure 1. Q-sorting template. In the current study, participants were required to rank 34 statements on the acceptability of innovations in dairy farming and dairy supply chain practices to achieve more sustainable low-input and organic dairy farming and supply chain systems. The 34 statements had to be sorted from "strongly like" $(+9)$ to "strongly dislike" $(+1)$.

the Q methodology requires participants to place only a limited number of the statements at the extremes of the scale. In this way, they must consider carefully which statements they feel most strongly about. In addition, as they work through the sorting exercise, participants compare every statement with every other statement. Hence, what is revealed is not just their attitude to specific statements, but their overall attitude to the topic under consideration.

The Q-sorting procedure started by asking participants "Which innovation would you most like, or dislike, seeing in organic and low-input farming"? Once completed, the participants were asked to review their Q-sorts and make any final adjustments to represent more accurately his/her point of view (McKeown and Thomas, 2013). The Q-sorting procedure was followed by the participants completing some written responses to a set of exploratory questions about their choices in the ranking of statements and then brief facilitated group or individual discussions. The information collected during the post-sort activities did not form part of the statistical analysis of the statement sorts. It was used to explain in more depth the participants' perception of the various statements/innovations and interpret the factors.

\section{Statistical Analysis}

The analysis of the Q-sorts was carried out using the software package PQMethod (Schmolck, 2002). Data analysis was undertaken at the country level. Factors were separately extracted for each country and then interpreted and analyzed at the country level (i.e., separately for each country). The first step in the analysis involved correlating every sort with every other sort. The sorts were then factor analyzed, applying the centroid factor extraction (Watts and Stenner, 2012) to reduce the data to a smaller number of defining sorts (maximum 8; Hall, 2008). In order "to maximize the amount of study variance explained" (Watts and Stenner, 2012) and to enhance the clarity of each factor extracted, a varimax rotation was then applied to the centroid solution (see Watts and Stenner, 2012). The rule from Brown (1980) was then applied to extract the significant factors. The product of the factor extraction is a table with the correlations between each Q-sort and each factor (i.e., the factor loadings; Watts and Stenner, 2012). It expresses the extent to which each Q-sort is associated with each factor extracted. Brown (1980) suggests that a significant factor loading at the 0.01 level is calculated using the equation $2.58 \times(1 \div \sqrt{\text { no. of statements }})$. This value was calculated as follows:

$2.58 \times(1 \div \sqrt{\text { no. of statements }})=2.58 \times(1 \div \sqrt{34})= \pm 0.442$.

Only 2 factors were extracted in each country involved (BE, FI, IT, and the UK), because in each unrotated factor matrix, the factor loadings indicated that 2 factors satisfy the rule from Brown (1980). The other 5 factors contained nonsignificant loadings or were on the borderline. Furthermore, only 2 factors explained most of the total variance. In addition, a scree test (plotting the eigenvalues on a line graph) was applied as the decision-making criterion. This criterion suggests that the number of factors to extract is indicated in the graph "by the point at which the line changes slope" (Watts and Stenner, 2012). Also, the 2-factor solution, compared with the 3 -factor one, provides a more con- 
sistent interpretation; the meanings included in the 2 factors better explains the different perspectives.

\section{RESULTS}

The factor arrays for each of the 2 factors in each country are presented in Table 2. The first-order factor analysis, defining different factors from BE, FI, IT, and the UK, was not intended to show whether any factor existed that was uniquely from 1 country (e.g., $\mathrm{BE}$ or uniquely FI), as comparisons were not possible at this stage. In this paper, we limited our presentation to the results of first-order factor analysis. A deeper study of country similarities of differences by means of second-order factor analysis (i.e., the factor analysis of the original 8 factors) was beyond the scope of this paper and will be pursued in further research. The factors that emerged from the analysis represent different attitudes or viewpoints on the discourse surrounding the topic being investigated. In each country, consensus statements (i.e., similarly liked or disliked between the 2 factors) and distinguishing statements (those that were polarized between the 2 factors) were identified (Table 3). A strong consensus existed between factors across countries as to which innovations were deemed to be unacceptable in organic and low-input dairy systems. These included improving forage quality and yields in low-input and organic dairy systems by GM plant breeding techniques (statement 18), developing designer dairy food from transgenic animals (statement 26 ), the acceleration of genetic selection using processes including recombination in vitro (statement 28), and innovations to speed up calf development from birth to maturity so that they can breed earlier (statement 33). In the post-sort discussions, the terms used to describe these innovations included "unnatural," "not safe," "not enough research done," "unknown impacts in future," and "ethically wrong." These terms were used across all supply chain members and all countries, when discussing the statements; for example,

Statement 18: UK consumer: “. . . not messing with the natural diet, it cannot produce natural milk."

Statement 26: BE producer: "We should have respect for the individual and not mess with their genes."

Statement 26: FI processor/retailer: "First of all, GMO is not an issue even in traditional production and considering organic production it feels like bad idea anyway. Manipulations related to animals are the most unethical."
The terms "unnatural" and "unsafe" were also identified in a report by Gaskell et al. (2010) as the main reasons given by the European citizens for the lack of acceptance of GM technology in food. In the same survey, Gaskell et al. (2010) found that between 1996 and 2010, there was a general downward trend in the acceptance of GM technologies in food, although fluctuations and degrees of difference existed between countries (e.g., Portugal, Spain, and Greece had marked decreases in acceptability, whereas in the UK, only a slight decrease was observed).

Alongside these strong feelings against these innovations, a certain degree of confusion existed among some participants as to what precisely the technologies were and what benefits might be achieved from them in lowinput and organic systems:

Statement 26: IT consumer: “. . . transgenic isn't natural but I don't think it is dangerous or I don't know."

Gaskell et al. (2006), based on 2005 Eurobarometer data, stated that more support exists for pharmaceutical and industrial biotechnology than agricultural biotechnology, because people can see the potential benefits for themselves and society in general. According to the poll (Gaskell et al., 2006), citizens have slight concerns about the usefulness and moral aspects of the GM products in agriculture, and notable concerns about the perceived risks; therefore, until their concerns are alleviated or the perceived benefits outweigh them, the public will continue to be skeptical about biotechnology in food production.

The majority of the participants who were members of organic supply chains automatically rejected any innovations that were in contradiction with the European organic farming regulations (European Communities, 2007). Only 1 recently converted organic farmer in the UK was an exception:

Statement 26: UK producer: "I'm not against some of the GM techniques compared to a lot of organic farmers; I'm a fairly late convert to organics, one of those perceived to be in it for the money!"

Many of the participants who did not identify themselves as being "organic" consumers or participating in organic supply chains still were of the opinion that these technologies were unacceptable. One Belgian processor/retailer summed up the general feelings of organic supply chain members:

BE processor/retailer: "All of these are in direct opposition with the philosophy of organic food. 
Table 2. Factor arrays for each of the 2 factors in each country

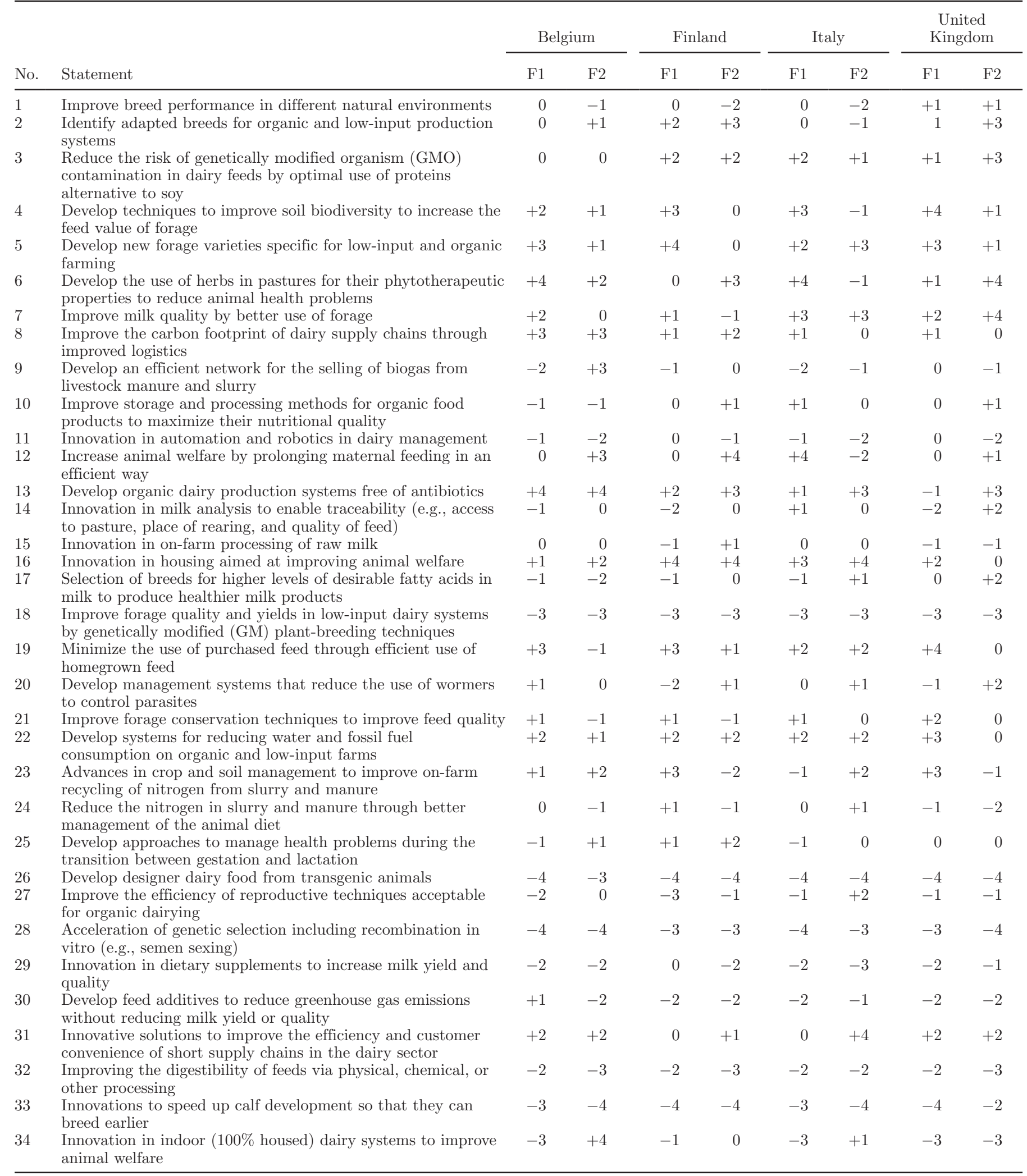

${ }^{1} \mathrm{~F} 1=$ factor $1 ; \mathrm{F} 2=$ factor 2. 
Table 3. Summary of consensus and distinguishing statements ${ }^{1}$

\begin{tabular}{|c|c|c|c|c|c|c|c|c|}
\hline Statement & \multicolumn{2}{|c|}{ Belgium } & \multicolumn{2}{|c|}{ Finland } & \multicolumn{2}{|c|}{ Italy } & \multicolumn{2}{|c|}{ United Kingdom } \\
\hline Negative & \multicolumn{2}{|c|}{$\begin{array}{c}8,13 \\
18,26,28,32,33\end{array}$} & \multicolumn{2}{|c|}{$\begin{array}{c}16 \\
18,26,28,33\end{array}$} & \multicolumn{2}{|c|}{$\begin{array}{c}7,16,19,22 \\
18,26,28,33\end{array}$} & \multicolumn{2}{|c|}{$\begin{array}{c}\text { None } \\
18,26,28,34\end{array}$} \\
\hline \multicolumn{9}{|l|}{ Distinguishing statements } \\
\hline Positive & $5,6,19$ & $34,9,12$ & $4,5,19,23$ & $2,6,12,13$ & $4,6,12$ & 31 & $4,19,22,23$ & $2,3,6,13$ \\
\hline
\end{tabular}

${ }^{1} \mathrm{~F} 1=$ factor $1 ; \mathrm{F} 2=$ factor 2. A full list of innovations related to the statement numbers is available in Table 2.

Genetic selection (statement 28), transgenic animals (statement 26), genetically modified (statement 18), animals staying inside (statement 34), sped-up calf development (statement 33) are all not acceptable in organic food production. Everything that deviates from the natural way is unacceptable in our opinions."

\section{Belgium}

Positive consensus statements included those related to antibiotic free production (statement 13) and new logistics for reducing the carbon footprint (statement 8; Table 3). Negative consensus include those previously described (statements 18, 26, 28, and 33) and in addition statement 32 , improving the digestibility of feeds via physical, chemical, or other processing. Factor 1 explained $29 \%$ of the study variance and 13 participants were significantly associated with this factor. Factor 2 explained $25 \%$ of the study variance and 8 participants were significantly associated with this.

Factor 1-Free-Range Forage Support. Factor 1 refers to innovation related to feeding. By promoting new advancements in agronomic techniques, a more sustainable animal husbandry could be developed. Some of the key tools to "greener" grazing management include developing the use of medicinal herbs in pastures to reduce animal health problems (statement 6 ) and the use of new forage varieties specific for lowinput and organic farming (statement 5). Efficiency is also an important issue, whether by means of reducing purchased feed by efficient use of forage or by means of new varieties (statements 19 and 5). The key message here is to reduce the costs of feed harvest and storage and, at the same time, keep cows on pastures to have more on-farm control of the feeding and to improve animal health and have fewer diseases. Innovations in housing for $100 \%$ housed dairy herds, aiming to improve welfare (statement 34 ), are perceived as not appropriate for low-input or organic systems, regardless of whether they could be designed for good welfare or not.
Factor 2-Efficient Indoor Welfare Advocacy. Factor 2 groups participants that value innovations that they feel may improve animal welfare, especially in indoor dairy systems. This line of innovation is indeed consistent with prolonged maternal feeding and production of biogas from slurry and manure (statements 34,12 , and 9). This factor also stresses efficiency improvements.

Post-sort comments and narratives helped in pointing out the crucial role of the interpretation of the attribute "indoor" in this factor. Respondents loading onto factor 2 appeared to accept that 100\% indoor housing systems already exist in organic and low-input dairy farming and that welfare innovation, specifically facilitating access to the outdoors, is required to provide the animals in these systems with higher levels of welfare. This down-to-earth, practical-oriented viewpoint is clearly very different from factor 1 , where free range is seen as a non-negotiable prerequisite for organic and low-input dairying:

Statement 34: BE consumer: "Animal welfare is important. Animals should have access to outdoors, enough space, no painful method at slaughter. I know that this has an impact on the quality of the milk as well. I think a healthy animal will produce healthier milk."

This perhaps demonstrates a lack of understanding by that consumer of what $100 \%$ housed systems are and particularly its acceptability under organic regulations and the high levels of inputs required to make these systems economically viable (Morrison, 2003). It is noteworthy that, in Belgium, consumers in the $\mathrm{P}$ set mainly loaded onto factor 2 , whereas factor 1 was mainly associated with producers and retailers.

\section{Finland}

There was only one positive consensus statement in FI: statement 16 (innovation in housing to improve animal welfare; Table 3). As described previously, both 
Finnish factors were positively associated with statements 18, 26, 28, and 33. In FI, a 2-factor solution accounted for 28 Q-sorts and $54 \%$ of the total variance. Factor 1 explained $30 \%$ of the study variance and 17 participants were significantly associated with this factor. Factor 2 explained $24 \%$ of the study variance and 10 participants were significantly associated with this second factor. Only 1 Q-sort was not associated significantly with either factor. Both factors were distinguishable by positive statements only, as no negative distinguishing statements were associated with any of the factors.

Factor 1-Home-Grown Feed and Soil Management. In FI, factor 1 exhibited interest in innovations in crop and soil management (statements 4 and 23) and innovations in feeding for low-input and organic systems (statements 19 and 5). Factor 1 represented a view of organic and low-input dairying based on selfsufficiency and sound crop/soil management.

Factor 2-Natural Animal Health and Welfare Purism. For this factor, animal health and welfare statements 2, 6, 12, and 13 were distinguishing. Factor 2 was the position of those who approached animal health and welfare sensu stricto: adapted breeds for organic and low-input production systems would be naturally healthier and stronger, while allowing for prolonged maternal feeding. Antibiotics should be banned by developing the use of herbs in pastures for their medicinal properties.

Unlike respondents from most other countries in the study, Finnish respondents were relatively neutral about statement 34 [innovation in indoor dairy systems $(100 \%$ housed) to improve animal welfare]. This could perhaps be due to the fact that typical dairy systems in Finland house cows for extended periods of time due to climatic conditions and Finland has welfare legislation (implemented in 2006) stating that cattle must have access to pasture or alternative exercise areas outdoors for a minimum period of time during the summer $(6 \mathrm{wk}$ to 4 mo, depending on location; Van den Pol-van Dasselaar, 2008). It appears that the existence of this legislation in Finland is enough to reassure low-input and organic dairy supply chain members that $100 \%$ housed systems will not be allowed; therefore, innovations related to $100 \%$ housed systems are redundant in Finland. Innovation to improve welfare generally in housing, however, was ranked very highly by both factors in FI and was the only positive consensus statement in FI.

\section{Italy}

Both factors ranked improving milk quality by better use of forage (statement 7), innovation in housing aimed at improving welfare (statement 16), minimizing the use of purchased feed through efficient use of homegrown feed (statement 19), and systems for reducing water and fossil fuel consumption on organic and lowinput dairy farms (statement 22) highly. As with BE and FI, the majority of Italian participants did not like innovations 18, 26, 28, and 33. Factor 1 explained $34 \%$ of the study variance and $16 \mathrm{Q}$-sorts were significantly associated with this factor. Factor 2 explained $14 \%$ of the study variance and 7 Q-sorts were significantly associated with this. Only 1 participant did not load onto either of the 2 factors.

Factor 1-Arcadian Dream. This factor supported "natural" feeding to promote animal health and welfare and scorned most types of innovations in dairy management. The factor grouped the viewpoints of those who felt that innovation in feeding is only acceptable when it follows natural cycles [e.g., if it increases the value of forage, if it prolongs maternal feeding, or if it promotes animal health by herbs in pastures (statements 4, 12, and 6)].

Factor 2-Short Supply Chain Focus. Factor 2 was fully characterized by just 1 statement: "Innovative solutions to improve the efficiency and customer convenience of short supply chains in the dairy sector" (statement 31), which was highly ranked. This factor only loaded 1 retailer Q-sort out of 7 .

Italy was unique in having a group of supply chain members loading on a supply chain efficiency factor and this is perhaps indicative of the higher number of short dairy supply chains and more local and artisan producers and processors in IT compared with the other countries studied. This is supported by Eurobarometer data (European Commission, 2012) that indicates that specialist regional production is high in IT compared with other EU15 countries. Taken together, both factors show a view of organic and low-input farming based on traditional family farms, where the cows are mainly forage fed and the value added is achieved by a direct relationship with the customers.

\section{United Kingdom}

Uniquely to the UK, no positive consensus statements were identified (Table 3). However, strong consensus was observed over disliked statements $(18,26$, and 28, as seen in other countries) and both factors also recognized the importance of access to the outdoors and grazing in dairy production and disliked statement 34 ["Innovation in indoor ( $100 \%$ housed) dairy systems to improve animal welfare"].

Factor 1 explained $28 \%$ of the study variance and 15 Q-sorts were significantly associated with this factor. Factor 2 explained $21 \%$ of the study variance and 11 Q-sorts were significantly associated with this factor. 
Factor 1-Free-Range Ecological Foraging. This factor represented the viewpoint of those who see innovations in forage-fed dairy systems as the key for improving the farming systems in terms of efficient production. In addition, this group also liked the idea of reducing wastes and increasing the efficient use of water and fossil fuel (statement 22).

Factor 2-Natural Animal Health and Welfare Advocacy. This factor valued the "naturalness" of the farming system, including the use of breeds adapted to low-input and organic systems (statement 2), reducing the risk of genetically modified organism (GMO) contamination by using alternative protein feeds to soy (statement 3), increasing the use of herbs in pasture to improve animal health (statement 6), and reducing the amount of antibiotics used in dairy herds (statement 13). The majority of participants loaded onto this factor were retailers and processors, which may be particularly concerned with reducing the risk of contaminants (GMO and antibiotics) in their products.

The distinguishing statements for both factors showed very close similarities to FI. One important difference is the very negative ranking given by both UK factors to statement 34 ["Innovation in indoor ( $100 \%$ housed) dairy systems to improve animal welfare"]. In the UK, dairy cows are typically only housed during the winter months (October/November to March) and, therefore, housing animals year round is unusual practice and felt to have a negative impact on the welfare of dairy cows in the context of the 5 animal welfare freedoms as defined by the UK Farm Animal Welfare Council (Farm Animal Welfare Council, 2009). The majority of the dairy cows in the UK are fed off grazed pasture [less than $5 \%$ of dairy cattle were zero grazed in 2005, although this was increasing (Van den Pol-van Dasselaar, 2008)] during the summer months and, therefore, access to this relatively inexpensive source of feed is important.

\section{DISCUSSION}

Across all countries, consumers tended to load more on factors where the main theme was high animal welfare. Producers and retailers/processors, on the other hand, tended to load more on factors related to feed efficiency, feed quality, and efficiency of production. Innovations to improve animal welfare, however, were still also important to this group.

In all countries, at least 1 factor prioritized animal health or welfare, or both, as a key theme, but in each instance in combination with another theme. For example, in BE, animal welfare and environmental efficiency were prioritized together in 1 factor; in FI, IT, and the UK, the emphasis was on more natural systems and animal health, with additional interest in feed quality in Italy. This strong emphasis on animal welfare is unsurprising, given the results of previous studies carried out by the European Commission (European Commission, 2005, 2007) and the Welfare Quality project (Kjærnes et al., 2007), which confirm that animal welfare is an issue of considerable significance for European consumers and that European citizens show a strong commitment to animal welfare. At the same time, the retailers and producers are increasingly recognizing that efforts to meet consumer concerns and requirements in the animal welfare area actually represent a business opportunity and may, thereby, be profitably incorporated in the production strategies of any agri-food company or chain (Blokhuis et al., 2008). Animal health and welfare can also have a direct effect on product quality [e.g., high stress levels, resulting in dry firm dark (DFD) meat; FAO, 2001] and high SCC in milk (Caroprese et al., 2006), which again highlights the importance of innovations to improve animal health and welfare to the whole supply chain.

The other factor innovation themes that were of importance were feed and forage quality in BE and IT and farm and soil management in FI and the UK. However, even though different factors resulted from the analysis, some innovation statements were common to all 4 of these factors, including growing better quality forage and increasing the amount of homegrown forage to replace purchased feed.

The consensus statements highlight the synergies in the supply chain and identify specific innovations that are acceptable or unacceptable to the majority within the supply chain. In all countries, a clear aversion exists to all GM-related innovations. Both factors in the UK rejected 100\% indoor-housing solutions, which are controversial in BE and IT (one factor advocating them, the other strongly rejecting). In the Belgian and, to some extent, in the Italian case, innovations that allow antibiotic free dairy production are important for both factors.

The list of consensus statements is always quite long and many appear in both factors across all countries. In all countries surveyed, an overwhelming dislike was expressed of those innovations related to practices that are perceived to be "unnatural." They include activities improving the forage quality and yields in low-input and organic dairy systems by GM plant-breeding techniques, developing designer dairy food from transgenic animals, accelerating genetic selection using processes that includes recombination in vitro, and innovations to speed up calf development from birth to maturity. It is perhaps unsurprising that these technologies are rejected, as they do not comply with current organic principles or regulations (European Communities, 2007); in 
any case, they were firmly rejected by all participants in the study. In all countries 2 main themes dominated the innovations that were liked; these were innovations to improve animal welfare and innovations to improve feed and forage quality and reduce the use of purchased concentrate feed. The latter highlights the importance of good-quality forage in low-input and organic dairy systems and also reflects consumers' desire for more "naturally" fed animals. In general, across countries, the viewpoints on organic and low-input dairying innovations with respect to breed selection and adaptation were relatively neutral, with the exception of the UK and FI, where identification of specific adapted breeds appears to be relevant for 1 factor. Although innovations to improve animal welfare confirm the findings of previous studies looking specifically at consumer attitudes to animal welfare (European Commission, 2005, 2007), our results provide novel information on emerging pathways of innovation that would meet the requirements of stakeholders in the surveyed countries.

\section{CONCLUSIONS}

Our Q-study on the acceptability of innovations in low-input and organic dairy farm management and supply chain practices revealed that substantial similarity of viewpoints exists across countries. Animal welfare always characterized one factor, whereas the other factor was more country dependent. However, the correlation index between the factors in each country was positive and quite high (FI: 0.6879, IT: 0.6595, BE: 0.6697, and the UK: 0.6798). Albeit qualitative in nature, the results of the study indicate that the preference of low-input and organic dairy supply chain members in BE, FI, IT, and the UK regarding innovations to improve the sustainability of their supply chains lies in developing innovations to improve animal welfare and to improve forage quality to be able to reduce the need for purchased concentrate feeds. Our investigation confirms no interest exists within these sectors for innovations based on biotechnology. Further research is needed to confirm our findings in other countries and to fully investigate the antecedents of these attitudes in larger samples.

\section{ACKNOWLEDGMENTS}

The authors gratefully acknowledge the financial support of the EU Commission for the research project "Sustainable Organic and Low-Input Dairying" (EUFP7 SOLID). The views expressed here are not in any way attributable to the EU Commission but are solely the responsibility of the authors. The authors thank the different stakeholders (retailers, processors, and farm- ers) as well as consumers involved in the survey. Special thanks go to Ellen Van Loo and Terhi Latvala, for their help with the data collection in Belgium and Finland, respectively.

\section{REFERENCES}

Barry, J., and J. Proops. 1999. Seeking sustainability discourses with Q methodology. Ecol. Econ. 28:337-345.

Bayliss, C., and T. Clay. 2006. Attitudes and decision making amongst Scottish organic farmers. Page 151 in What Will Organic Farming Deliver? Aspects of Applied Biology 79. C. Atkinson, B. Ball, D. H. K. Davies, R. Rees, G. Russell, E. A. Stockdale, C. A. Watson, R. Walker, and D. Younie, ed. Association of Applied Biologists, Warwick, UK.

Bello, D. C., R. Lohtia, and V. Sangtani. 2004. An institutional analysis of supply chain innovations in global marketing channels. Ind. Mark. Manage. 33:57-64.

Blokhuis, H. J., L. J. Keeling, A. Gavinelli, and J. Serratosa. 2008. Animal welfare's impact on the food chain. Trends Food Sci. Technol. 19:S79-S87.

Brook Lyndhurst. 2009. An Evidence Review of Public Attitudes to Emerging Food Technologies. A report carried out on behalf of the Social Science Research Unit, Food Standards Agency, UK. Brook Lyndhurst Ltd., London, UK.

Brown, S. R. 1980. Political subjectivity: Applications of Q methodology in political science. Yale University Press, London, UK.

Brown, S. R. 1993. A primer on Q methodology. Operant Subjectivity 16:91-138.

Brown, S. R., and U. Feist. 1992. Calibrating bilingual Q samples. Operant Subjectivity 15:105-115.

Carlson, E. D. 2000. A case study in translation methodology using the Health-Promotion Lifestyle Profile II. Public Health Nurs. $17: 61-70$.

Caroprese, M., M. Albenzio, A. Muscio, and A. Sevi. 2006. Relationship between welfare and udder health indicators in dairy ewes. Vet. Res. Commun. 30:83-94.

CEAS and EFNCP (Centre for European Agricultural Studies and European Forum on Nature Conservation and Pastoralism). 2000. The Environmental Impact of Dairy Production in the EU: Practical Options for the Improvement of the Environmental Impact. Accessed June 3, 2013. http://ec.europa.eu/environment/ agriculture/pdf/dairy.pdf.

Darnhofer, I., W. Schneeberger, and B. Freyer. 2005. Converting or not converting to organic farming in Austria: Farmer types and their rationale. Agric. Human Values 22:39-52.

Donner, J. C. 2001. Using Q Sorts in participatory processes: An introduction to the methodology. Social Development Papers 36:24-49.

Eden, S., C. Bear, and G. Walker. 2008. The sceptical consumer? Exploring views about food assurance. Food Policy 33:624-630.

EEA (European Environment Agency). 2005. Agriculture and environment in EU-15 - The IRENA indicator report. EEA, Copenhagen, Denmark.

European Commission. 2005. Attitudes of consumers towards the welfare of farmed animals. Eurobarometer, Brussels, Belgium.

European Commission. 2007. Attitudes of EU citizens towards animal welfare. Eurobarometer, Brussels, Belgium.

European Commission. 2008. Towards a coherent strategy for a European Agricultural Research Agenda. Communication from the Commission to the Council, the European Parliament, the European Economic and Social Committee and the Committee of the Regions. $\operatorname{COM}(2008) 862$, Brussels. Accessed July 10, 2013. http://eur-lex.europa.eu/LexUriServ/LexUriServ.do?uri=COM:2 008:0862:FIN:EN:PDF.

European Commission. 2012. Europeans' attitudes towards food security, food quality and the countryside. Special Eurobarometer 389. Eurobarometer, Brussels, Belgium.

European Communities. 2007. Council Regulation (EC) No. 834/2007 of 28 June 2007 on organic production and labelling of organic products and repealing Regulation (EEC) No 2092/91. Official 
Journal of the European Communities 20.7.2007. L189/1, 1-23. European Communities, Brussels, Belgium.

Falconer, K. 2000. Farm-level constraints on agri-environmental scheme participation: A transactional perspective. J. Rural Stud. 16:379-394.

FAO (Food and Agriculture Organization of the United Nations). 2001. Guidelines for the humane handling, transport and slaughter of livestock. RAP Publication 2001/4. FAO, Regional Office for Asia and the Pacific, Bangkok, Thailand.

Farm Animal Welfare Council. 2009. Farm Animal Welfare in Great Britain: Past, Present and Future. Farm Animal Welfare Council, London, UK. Accessed Feb. 26, 2013. http://www.fawc.org.uk/ pdf/ppf-report091012.pdf.

Gaskell, G., A. Allansdottir, N. Allum, C. Corchero, C. Fischler, J. Hampel, J. Jackson, N. Kronberger, N. Mejlgaard, G. Revuelta, C. Schreiner, S. Stares, H. Torgersen, and W. Wagner. 2006. Europeans and Biotechnology in 2005: Patterns and Trends. Eurobarometer 64.3. A report to the European Commission's Directorate-General for Research. Accessed Feb. 26, 2013. http://ec.europa.eu/ research/press/2006/pdf/pr1906_eb_64_3_final_report-may2006 _en.pdf.

Gaskell, G., S. Stares, A. Allansdottir, N. Allum, P. Castro, Y. Esmer, C. Fischler, J. Jackson, N. Kronberger, J. Hampel, N. Mejlgaard, A. Quintanilha, A. Rammer, G. Revuelta, P. Stoneman, H. Torgersen, and W. Wagner. 2010. Europeans and Biotechnology in 2010 - Winds of Change? A report to the European Commission's Directorate-General for Research-Science in Society and Food, Agriculture \& Fisheries, \& Biotechnology. Publications Office of the European Union, Luxembourg.

Hall, C. 2008. Identifying farmer attitudes towards genetically modified (GM) crops in Scotland: Are they pro- or anti-GM? Geoforum 39:204-212.

Harper, G. C., and A. Makatouni. 2002 Consumer perception of organic food production and farm animal welfare. Brit. Food J. 104:287-299.

Janssen, S., E. Andersen, I. N. Athanasiadis, and M. K. van Ittersum. 2009. A database for integrated assessment of European agricultural systems. Environ. Sci. Policy 12:573-587.

Kjærnes, U., E. Roe, and B. Bock. 2007. Societal concerns on farm animal welfare. Pages 13-18 in Assuring animal welfare: From societal concerns to implementation. I. Veissier, B. Forkman, and B. Jones ed. Proc. of Second Welfare Quality Stakeholder Conference, Berlin, Germany. Animal Sciences Group of Wageningen UR, Lelystad, the Netherlands.

Knaus, W. 2009. Dairy cows trapped between performance demands and adaptability. J. Sci. Food Agric. 89:1107-1114.

Ledgard, S. F., and J. Luo. 2008. Nitrogen cycling in intensively grazed pastures and practices to reduce whole-farm nitrogen losses. Pages 292-297 in Multifunctional Grasslands in a Changing World, Volume 1: XXI International Grassland Congress and VIII International Rangeland Congress, Hohhot, China. Guangdong People's Publishing House, China.

Makatouni, A. 2002. What motivates consumers to buy organic food in the UK? Results from a qualitative study. Br. Food J. 104:345352 .

McKeown, B., and D. B. Thomas. 2013. Q Methodology. 2nd ed. Sage Publications Inc., Newbury Park, CA.

Midmore, P., S. Naspetti, A.-M. Sherwood, D. Vairo, M. Wier, and R. Zanoli. 2005 Consumer attitudes to quality and safety of organic and low input foods: A review. Integrated Project No. 506358, Improving quality and safety and reduction of cost in the European organic and 'low input' food supply chains (QLIF). University of Wales, Aberystwyth, Wales, UK. Accessed June 7, 2013. http:// www.qlif.org/research/sub1/pub/1_1_1_UWAL.pdf.

Midmore, P., S. Padel, H. McCalman, J. Isherwood, S. Fowler, and N Lampkin. 2001. Attitudes towards Conversion to organic production systems: A study of farmers in England. Accessed July 11, 2013. http://orgprints.org/10817/1/Attitude_survey.pdf.

Moakes, S., and N. Lampkin. 2009. Welsh Organic Production and Market Report 2008. Institute of Biological, Environmental and
Rural Sciences, Aberystwyth University. Accessed July 25, 2013 http://www.organiccentrewales.org.uk/uploads/producersurvey report2008.pdf.

Morrison, V. 2003. Zero grazing. Dairy Technical Note 16. Greenmount College of Agriculture and Horticulture, Department of Agriculture and Rural Development, Antrim. UK.

Nauta, W. J., T. Baars, and H. Bovenhuis. 2006. Converting to organic dairy farming: Consequences for production, somatic cell scores and calving interval of first parity Holstein cows. Livest. Sci. 99:185-195.

Nicholas, P., A. Sundrum, and S. Padel. 2007. Guidance notes to operators including recommendations in relation to nutrient supply. Research to support the revision of the EU Regulation on organic agriculture. Project No. SSPE-CT-2004-502397. Accessed July 25, 2013. http://www.organic-revision.org/pub/D43\%20Guidance\%20 notes $\% 2023 \% 20$ October\%202007.pdf.

Padel, S. 2001. Conversion to organic milk production: The change process and farmers' information needs. PhD Thesis. Institute of Royal Studies, University of Wales, Aberystwyth, UK.

Padel, S. and C. Foster. 2005. Exploring the gap between attitudes and behaviour: Understanding why consumers buy or do not buy organic food. Br. Food J. 107:606-625.

Regouin, E. 2003. To convert or not to convert to organic farming. Pages 227-235 in Organic Agriculture Sustainability, Markets and Policies. Organisation for Economic Cooperation and Development. CAB International, Wallingford, UK.

Roche, J. R., N. C. Friggens, J. K. Kay, M. W. Fisher, K. J. Stafford, and D. P. Berry. 2009. Body condition score and its association with dairy cow productivity, health, and welfare. J. Dairy Sci. 92:5769-5801

Ronteltap, A., J. C. M. van Trijp, R. J. Renes, and L. J. Frewer. 2007. Consumer acceptance of technology-based food innovations: Lessons for the future of nutrigenomics. Appetite 49:1-17.

Schiere, J. B., J. De Wit, F. A. Steenstra, and H. Van Keulen. 1999. Design of farming systems for low input conditions: Principles and implications based on scenario studies with feed allocation and livestock production. Neth. J. Agric. Sci. 47:169-183.

Schmid, O., S. Dabbert, C. Eichert, V. Gonzálvez, N. Lampkin, J. Michelsen, A. Slabe, R. Stokkers, M. Stolze, C. Stopes, P. Wollmuthová, D. Vairo, and R. Zanoli. 2008. Organic Action Plans. Development, implementation and evaluation. A resource manual for the organic food and farming sector. Research Institute of Organic Agriculture, Frick, Switzerland and European Union Group of the International Federation of Organic Agriculture Movements (IFOAM), Brussels, Belgium.

Schmolck, P. 2002. PQMethod Manual. Accessed Feb. 26, 2013. http:// schmolck.userweb.mwn.de/qmethod/pqmanual.htm.

Smit, A. H., P. J. Driessen, and P. Glasbergen. 2009. Conversion to organic dairy production in the Netherlands: Opportunities and constraints. Rural Sociol. 74:383-411.

Smith, E., and T. Marsden. 2004. Exploring the "limits to growth" in UK Organics: Beyond the statistical image. J. Rural Stud. 20:345-357.

Vaarst, M., S. Padel, D. Younie, M. Hovi, A. Sundrum, and C. Rymer. 2008. Animal health challenges and veterinary aspects of organic livestock farming identified through a 3 year EU Network project. Open Vet. Sci. J. 2:111-116.

Van den Pol-van Dasselaar, A., T. V. Vellinga, A. Johansen, and E. Kennedy. 2008. To graze or not to graze, that's the question. Grassland Sci. Eur. 13:707-716.

Watts, S., and P. Stenner. 2012. Doing Q Methodological Research: Theory, Method and Interpretation. Sage Publications Ltd., London, UK.

Zollitsch, W., T. Kristensen, C. Krutzinna, F. MacNaeihde, and D. Younie. 2004. Feeding for health and welfare: The challenge of formulating well-balanced rations in organic livestock production. Pages 329-356 in Animal Health and Welfare in Organic Agriculture. M. Vaarst, S. Roderick, V. Lund, and W. Lockeretz ed. CAB International, Wallingford, UK. 